\title{
BUDIDAYA PEMBESARAN KEPITING BAKAU Scylla tranquebarica (Fabricius, 1798) HASIL PEMBENIHAN PADA LOKASI TAMBAK YANG BERBEDA
}

\author{
Muhammad Nur Syafaat* dan Gunarto \\ Balai Riset Perikanan Budidaya Air Payau dan Penyuluhan Perikanan \\ (Naskah diterima: 15 Desember 2016; Revisi final: 27 November 2017; Disetujui publikasi: 28 November 2017)
}

\begin{abstract}
ABSTRAK
Kegiatan pembesaran kepiting bakau hasil pembenihan di tambak masih terbatas dan pada umumnya masih merupakan kegiatan penelitian. Tujuan penelitian ini adalah untuk mengetahui pertumbuhan, sintasan, produksi, dan membuat analisis usaha pembesaran krablet kepiting bakau hasil pembenihan pada beberapa lokasi tambak tradisional. Penelitian dilakukan di tiga lokasi tambak yaitu Maros, Pangkep, dan Polewali Mandar (Polman). Tambak yang digunakan pada setiap lokasi merupakan tambak tradisional berkonstruksi tanah dengan sistem penggantian air berdasarkan pasang surut. Krablet kepiting bakau dengan kisaran bobot 0,05-0,1 g/ekor ditebar dengan kepadatan 0,24 ekor $/ \mathrm{m}^{2}$ dan 0,27 ekor $/ \mathrm{m}^{2}$ untuk Kabupaten Pangkep dan Polman secara berurutan sedangkan pada Kabupaten Maros dengan kepadatan 0,53 ekor $/ \mathrm{m}^{2}$. Jenis pakan yang diberikan yaitu ikan rucah atau ikan liar yang ada di sekitar lokasi tambak dengan dosis $5 \% 10 \%$ dari biomassa dan diberikan dua atau tiga hari sekali. Hasil penelitian menunjukkan bahwa pertumbuhan kepiting bakau di tiga lokasi pada bulan ketiga diperoleh bobot akhir rata-rata dengan kisaran 131,05199,50 g/ekor (163,17 \pm 34,42); sintasan 22\%36,94\% (30,41 \pm 7,65); dan produksi 79,25-272,12 kg/ha $(176,07 \pm 96,43)$. Keuntungan tertinggi diperoleh pada lokasi Maros yaitu Rp5.454.750,00/ha/siklus dan terendah di lokasi Polman yaitu Rp317.150,00/ha/siklus. Nilai R/C rasio untuk semua lokasi menunjukkan lebih besar dari satu yang berarti bahwa usaha pembesaran kepiting bakau di tambak menggunakan krablet asal hatchery merupakan usaha yang layak. Ketersediaan pakan yang cukup, keberadaan shelter, pergantian air secara rutin dan kondisi kualitas air yang optimal merupakan faktor penting yang perlu diperhatikan untuk meningkatkan produksi pada ketiga lokasi di samping meningkatkan kepadatan sampai $1 \mathrm{ekor} / \mathrm{m}^{2}$.
\end{abstract}

\section{KATA KUNCl: pembesaran; kepiting bakau; tambak}

ABSTRACT: The grow-out cultures of hatchery-produced mudcrab Scylla tranquebarica (Fabricius, 1798) cultured at different pond locations. By: Muhammad Nur Syafaat dan Gunarto

\begin{abstract}
The grow-out cultures of hatchery-produced mudcrab seed in pond are rare and mostly part of research activities. The purpose of this study was to determine the performance of growth, survival rate, production, and develop a business analysis of mudcrab (S. tranquebarica) grow-out culture in different pond locations using hatchery-reared seed. The study was conducted in three pond areas in Maros, Pangkep, and Polewali M andar (Polman). The ponds used in each location were traditional soil ponds with sufficient tidal system for water exchange. Crablets with a weight range of 0.05-0.1 $\mathrm{g}$ were reared in the ponds located in Pangkep, Polman and M aros with stocking densities of 0.24, 0.27 and 0.53 ind. $/ \mathrm{m} 2$, respectively. The feed used was trash fish or locally caught wild fish and given $5 \% 10 \%$ of the total crab biomass once every two or three days. The results showed that the average final weight of mudcrab in the three locations during three months rearing period was $131.05-199.50 \mathrm{~g} / \mathrm{ind}$. (163.17 \pm 34.42$)$ with survival rates of $22 \% 36.94 \%(30.41 \pm 7.65)$, and crab production of $79.25-272.12 \mathrm{~kg} / \mathrm{ha}(176.07 \pm 96.43)$. The highest profit was obtained by grow-out culture in Maros location (IDR 5,454,750/ha/cycle) followed by Pangkep location (IDR $4,624,400 /$ ha/cycle) and the lowest at Polman location (IDR 317,150/ha/cycle). The R/C ratio for all locations was greater than one which means that mudcrab culture in pond using seed from hatchery is economically feasibility.
\end{abstract}

\section{KEYWORDS: culture; mudcrab; pond}

\footnotetext{
\# Korespondensi: Balai Riset Perikanan Budidaya Air Payau dan Penyuluhan Perikanan. JI. Makmur Dg. Sitakka No.129, Maros 90512, Sulawesi Selatan, Indonesia.

Tel.: + 62411371544

E-mail: syafaat.mnur@gmail.com
} 


\section{PENDAHULUAN}

Eksploitasi kepiting bakau secara besar-besaran di alam telah mengindikasikan terjadinya over fishing (tangkap lebih) di beberapa wilayah Indonesia (Gunarto et al., 2016) sehingga pemerintah mengeluarkan aturan yang tegas melalui peraturan Menteri Kelautan dan Perikanan No.1/PERMEN-KP/2015 untuk membatasi kegiatan penangkapan. Produksi benih dari hatchery dan kegiatan pembesaran kepiting bakau yang menggunakan benih dari hatchery merupakan salah satu solusi dari adanya pembatasan kegiatan penangkapan kepiting bakau di alam. Penelitian terhadap berbagai aspek pembesaran benih yang berasal dari hatchery perlu dilakukan, misalnya transportasi benih kepiting dari laboratorium ke tambak dan pembesaran benih di tambak (Permadi \& Juwana, 2014).

Di Indonesia, kegiatan pembesaran kepiting bakau hasil pembenihan di tambak masih terbatas dan pada umumnya masih merupakan kegiatan penelitian di instalasi riset atau kegiatan penelitian di lahan masyarakat. Herlinah et al. (2010) melaporkan bahwasannya pembesaran krablet kepiting bakau hasil pembenihan dengan menggunakan jenis pakan ikan rucah dan gabungan antara pakan ikan rucah dan pelet udang memperoleh bobot akhir rata-rata yang lebih baik setelah dipelihara selama tiga bulan yaitu 122,5 g/ekor (sintasan 54,5\% dan 130,4 g/ekor (sintasan $52,3 \%$ secara berurutan dibandingkan perlakuan yang hanya menggunakan pakan pelet saja yaitu 97,8 g/ekor (sintasan 52\%. Widodo et al. (2010) mendapatkan sintasan sekitar 15\%dengan bobot akhir rata-rata 316 $\mathrm{g}$ setelah memelihara krablet kepiting bakau hasil pembenihan selama enam bulan di lahan mangrove dengan sistem silvofishery tanpa pemberian pakan tambahan. Hendrajat \& Gunarto (2013) meneliti mengenai perbandingan pertumbuhan krablet kepiting bakau S. olivacea dan S. paramamosain hasil pembenihan di tambak dan didapatkan pertumbuhan dari S. paramamosain cenderung lebih baik dibanding S. olivacea. Gunarto \& Syafaat (2015) melaporkan sintasan dan produksi pada pembesaran kepiting bakau hasil pembenihan dengan frekuensi pemberian pakan sekali per dua dan tiga hari tidak berbeda nyata dengan perlakuan yang diberi pakan setiap hari. Permadi \& Juwana (2014) mengkaji mengenai pembesaran krablet kepiting bakau hasil pembenihan di keramba jaring dasar di tambak dan diperoleh sintasan mencapai 48,79\% Sulaeman et al. (2010) melakukan ujicoba polikultur kepiting bakau dengan rumput laut dan dapat mencapai sintasan kepiting bakau $>60 \%$ selama tiga bulan pemeliharaan.

Di antara faktor penting yang dapat memengaruhi kegiatan pembesaran organisme budidaya pada satu lokasi adalah karakteristik dari tambak itu sendiri misalnya konstruksi pematang, adanya pintu pemasukan dan pembuangan air, kualitas air, dan lainnya yang dapat mendukung pertumbuhan organisme yang dibudidayakan pada lokasi tersebut. Lekang (2013) mengemukakan bahwa performa optimal dari unit-unit produksi (ed. misal wadah budidaya) merupakan hal penting karena membentuk sistem produksi dalam usaha budidaya. Berdasarkan hal tersebut di atas maka penelitian ini bertujuan untuk mengetahui pertumbuhan, sintasan, produksi, dan membuat analisis usaha pembesaran krablet kepiting bakau hasil pembenihan pada beberapa lokasi tambak tradisional.

\section{BAHAN DAN METODE}

Penelitian ini dilaksanakan di tiga lokasi, terdiri atas dua kabupaten di Provinsi Sulawesi Selatan yaitu Kabupaten Maros dan Kabupaten Pangkep dan satu lokasi di Provinsi Sulawesi Barat yaitu Kabupaten Polewali Mandar (Polman) (Gambar 1). Penggunaan tiga lokasi pada penelitian ini tidak dimaksudkan sebagai uji multilokasi mengingat banyaknya parameter yang berbeda antara ketiga lokasi. Penelitian ini dimaksudkan sebagai kegiatan ujicoba sekaligus sosialisasi budidaya kepiting bakau di tambak menggunakan benih dari hatchery. Tambak yang digunakan pada setiap lokasi merupakan tambak tradisional berkonstruksi tanah dengan sistem penggantian air berdasarkan pasang surut. Spesifikasi tambak ditunjukkan pada Tabel 1.

Krablet kepiting bakau dengan kisaran bobot 0,050,1 g ditebar dengan kepadatan 0,24 ekor $/ \mathrm{m}^{2}$ dan 0,27 ekor/m² untuk Kabupaten Pangkep dan Polman secara berurutan, sedangkan pada Kabupaten M aros dengan kepadatan 0,53 ekor $/ \mathrm{m}^{2}$. Pengangkutan krablet ke lokasi Pangkep dan Polman menggunakan styrofoam dengan metode kering (tanpa air). Styrofoam bagian dalam dilengkapi dengan shelter (pelindung) berupa waring hitam dan paranet (Gambar 2). Kondisi krablet dalam keadaan baik setelah menempuh perjalanan sekitar satu jam ke lokasi Kabupaten Pangkep dan sekitar lima jam ke Kabupaten Polman.

Jenis pakan yang diberikan selama pemeliharaan tiga bulan yaitu ikan rucah atau ikan liar yang ada di sekitar lokasi tambak dengan dosis 5\%10\% dari biomassa (mengacu pada penelitian Pillai et al., 2002; Muchlisin \& Azizah, 2009; Qomariyah et al., 2014; Gunarto \& Syafaat, 2015; Permadi \& Juwana, 2016) dan diberikan dua atau tiga hari sekali ( \pm tiga kali sepekan). Pertumbuhan kepiting bakau dipantau dengan melakukan sampling pertumbuhan setiap bulan untuk mengukur bobot, serta lebar dan panjang karapas. Pengukuran berat menggunakan timbangan 

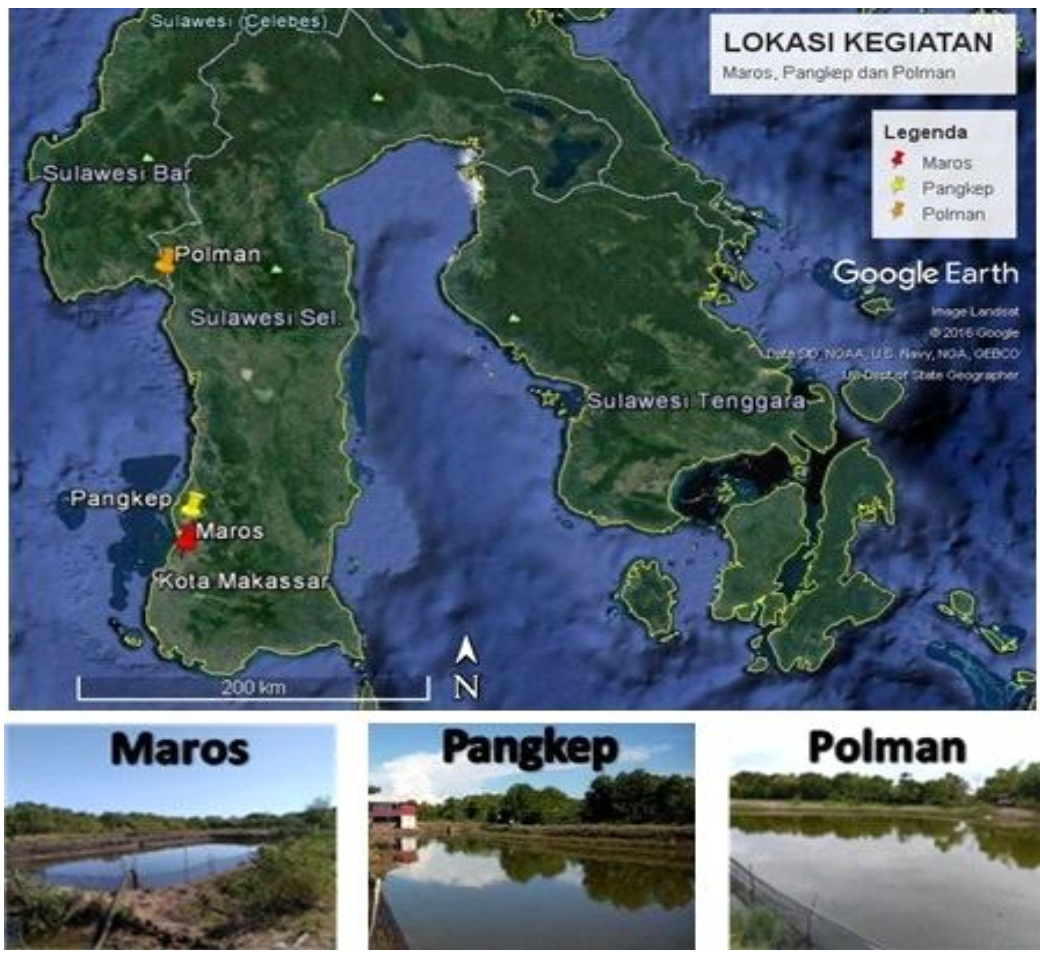

\section{Polman}

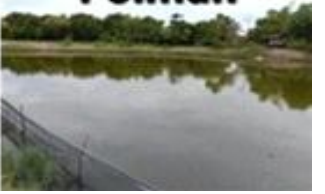

Gambar 1. Peta lokasi kegiatan (Maros, Pangkep, dan Polman).

Figure 1. Research site locations (M aros, Pangkep, and Polman).

Tabel 1. Karakteristik lokasi tambak kepiting bakau dengan benih berasal dari hatcheri

Table 1. Pond specifications for grow-out culture of mud crab seed from hatchery in the three locations

\begin{tabular}{|c|c|c|c|}
\hline Spesifikasi (Specification) & Maros & Pangkep & Polman \\
\hline $\begin{array}{l}\text { Luas tambak } \\
\text { Pond area }\left(\mathrm{m}^{2}\right)\end{array}$ & 800 & 5,000 & 2,800 \\
\hline $\begin{array}{l}\text { Salinitas } \\
\text { Salinity (ppt) }\end{array}$ & $20-30$ & $15-25$ & $10-20$ \\
\hline $\begin{array}{l}\text { Lebar saluran tambak } \\
\text { Channel width of pond }(\mathrm{m})\end{array}$ & 2 & 5 & 2 \\
\hline $\begin{array}{l}\text { Sumber air } \\
\text { Water sources }\end{array}$ & $\begin{array}{l}\text { Sungai lewat saluran } \\
\text { River through channel }\end{array}$ & $\begin{array}{l}\text { Sungai lewat saluran } \\
\text { River through channel }\end{array}$ & $\begin{array}{l}\text { Laut lewat saluran } \\
\text { Sea through channel }\end{array}$ \\
\hline $\begin{array}{l}\text { Jarak dari sumber air } \\
\text { Distance from water sources (m) }\end{array}$ & 300 & 10 & 100 \\
\hline
\end{tabular}

elektrik dengan ketelitian 0,01 g sedangkan lebar dan panjang karapas diukur menggunakan kaliper dengan ketelitian 0,1 mm.

Parameter yang diamati berupa pertumbuhan (ratarata pertumbuhan harian dan laju pertumbuhan spesifik) dan sintasan.

Rata-rata pertumbuhan harian (g) dihitung dengan persamaan:

Rata - rata pertumbuha $n$ harian $(g)=\frac{\left(W_{t}-W_{0}\right)}{t}$
Sedangkan laju pertumbuhan harian (\%hari) diukur dengan persamaan:

$$
\operatorname{SGR}(\% \text { hari })=\frac{\ln W_{t}-\ln W_{0}}{t} \times 100
$$

di mana:

$W_{t}=$ bobot akhir $(g)$

$\mathrm{W}_{0}^{\mathrm{t}}=$ bobot awal $(\mathrm{g})$

$\mathbf{t}^{0}=$ lama pemeliharaan (hari) 
Sintasan dihitung menggunakan persamaan:

$$
\text { Sintasan }=\frac{S 1}{S 0} \times 100
$$

di mana:

S1 = jumlah individu yang dipanen

SO = jumlah individu pada penebaran awal

(Muchlisin \& Azizah, 2009; Muchlisin et al., 2006)

Pada akhir kegiatan dilakukan analisis usaha pada ketiga lokasi yang mengacu pada Adi (2011) dan Syafaat et al. (2013) untuk mengetahui tingkat kelayakannya secara ekonomi. Perhitungan analisis usaha tidak memasukkan sewa lahan sebagai biaya investasi karena menggunakan lahan sendiri sedangkan biaya pakan dimasukkan pada biaya variabel walaupun pakan yang digunakan merupakan hasil tangkapan sendiri berupa ikan-ikan liar di sekitar lokasi.

Data pendukung yang dikumpulkan selama kegiatan yaitu data kualitas air, tanah, dan makrobentos. Kualitas air yang diamati berupa suhu, salinitas, dan oksigen. Pengukuran suhu dan oksigen menggunakan DO meter (The CyberScan D0 110 - Eutech ${ }^{\circledR}$ ) sedangkan salinitas diukur menggunakan refraktometer $\left(\right.$ Atago $\left.^{\circledR}\right)$. Setiap lokasi juga diambil sampel tanah untuk mengukur kandungan bahan organik, karbon organik, $\mathrm{N}$ total, $\mathrm{PO}_{4}$ (fosfat), dan $\mathrm{P}_{2} \mathrm{O}_{5}$ (difosfor pentaoksida/ diphosphor pentaoxide). Pengamatan makrobentos dilakukan dengan mengambil sampel tanah sebanyak tiga titik di setiap lokasi tambak kemudian disaring menggunakan saringan plastik dengan mesh size \pm 1 $\mathrm{mm}$. Identifikasi makrobentos mengacu kepada Arnold \& Birtles (1989) dan Smith \& Carlton (1975). Data pertumbuhan, sintasan, dan produksi kepiting bakau dari tiga lokasi yang diperoleh dibahas secara deskriptif dengan bantuan tabel dan grafik.

\section{HASIL DAN BAHASAN}

\section{Karakteristik Tambak, Kualitas Air, Tanah, dan Komposisi Makrozoobentos}

Tambak yang digunakan pada penelitian ini seluruhnya adalah tambak tradisional dan berada dekat dengan areal mangrove. Jenis tambak tradisional dipilih karena dianggap memiliki kondisi yang hampir sama dengan habitat kepiting bakau di alam, selain itu, lokasi tambak juga dipasangi waring hitam di sekelilingnya untuk mencegah keluarnya kepiting bakau.

Beberapa parameter kualitas air yang dimonitor secara bulanan yaitu suhu, salinitas, dan DO. Masa pemeliharaan kepiting bakau yang bertepatan dengan musim hujan menyebabkan kondisi salinitas yang rendah pada setiap lokasi khususnya pada masa awal pemeliharaan namun suhu dan DO yang diperoleh cukup baik untuk daerah Polman. Shelley \& Lovatelli (2011) menjelaskan bahwa budidaya kepiting bakau pada kondisi salinitas yang rendah (5-12 ppt) dapat mengakibatkan sintasan yang rendah dan moulting yang lambat sehingga tambak harus diisi dengan air payau sampai air laut sepenuhnya (10-35 ppt).

Pengukuran kualitas tanah dimaksudkan untuk mengetahui daya dukung tanah tambak pada setiap lokasi untuk kegiatan budidaya sebagaimana yang disajikan pada Tabel 2 dan juga untuk mengetahui pengaruhnya terhadap komposisi makrozoobentos (Tabel 3). Hasil pengamatan menunjukkan nilai yang lebih tinggi pada lokasi tambak di Maros untuk setiap parameter tanah yang diukur dibandingkan dengan lokasi lainnya. Perbedaan kualitas tanah yang diperoleh pada ketiga lokasi kemungkinan memiliki keterkaitan dengan keberadaan makrozoobentos pada ketiganya khususnya ketersediaan bahan organik. Pong-masak
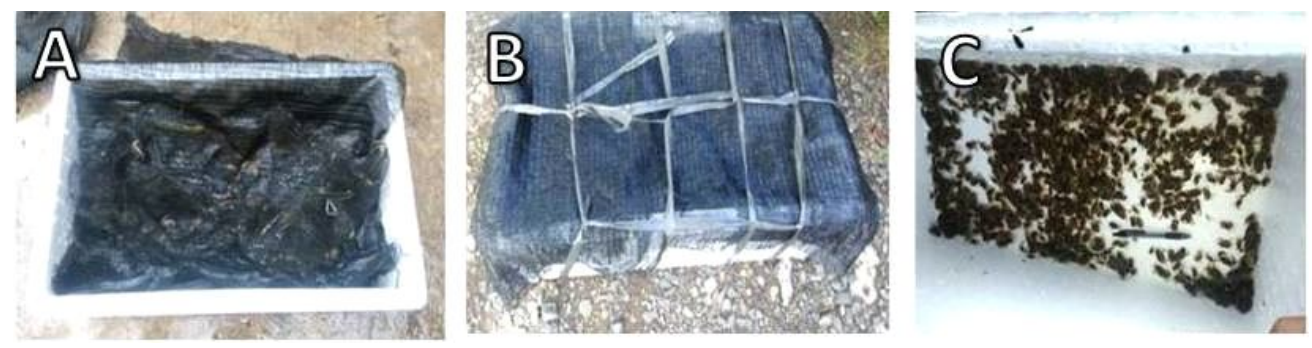

Gambar 2. Wadah pengangkutan krablet; A) shelter (berupa paranet) dalam styrofoam, B) boks styrofoam berisi krablet siap kirim, C) kondisi krablet saat tiba di lokasi.

Figure 2. Crablet transportation container; A) shelter (using paranet) in styrofoam, B) crablet box ready to send, C) crablet condition upon arrival at the location. 
Tabel 2. Hasil pengamatan parameter kualitas air dan tanah pada tiga lokasi

Table 2. Results of soil and water parameters measurement at three locations

\begin{tabular}{|c|c|c|c|}
\hline \multirow{2}{*}{ Parameter (Parameters) } & \multicolumn{3}{|c|}{ Lokasi tambak (Pond location) } \\
\hline & Maros & Pangkep & Polman \\
\hline \multicolumn{4}{|l|}{ Kualitas air (Water quality) } \\
\hline Oksigen terlarut (Dissolved oxygen) (mg/L) & $\mathrm{nm}$ & $\mathrm{nm}$ & $9.55-11.53$ \\
\hline Salinitas (Salinity) (ppt) & $10-30$ & $15-25$ & $10-21$ \\
\hline Suhu (T emperature ) $\left({ }^{\circ} \mathrm{C}\right)$ & $\mathrm{nm}$ & $\mathrm{nm}$ & $31.3-32.6$ \\
\hline \multicolumn{4}{|l|}{ Kualitas tanah (Soil quality) } \\
\hline Bahan organik (Organic matter) $(\%)$ & 9.04 & 5.14 & 1.93 \\
\hline Karbon organik (Organic carbon) ( $\%$ & 5.24 & 2.98 & 1.12 \\
\hline $\mathrm{N}$ total $(\mathrm{N}$ total $)(\%)$ & 0.24 & 0.2 & 0.12 \\
\hline Fosfat (Phosphate) $\left(\mathrm{PO}_{4}\right)(\mathrm{mg} / \mathrm{L})$ & 97.48 & 62.16 & 39.86 \\
\hline Difosfor pentaoksida (Diphosphor pentaoxide) $\left(\mathrm{P}_{2} \mathrm{O}_{5}\right)(\mathrm{mg} / \mathrm{L})$ & 72.85 & 46.46 & 29.79 \\
\hline
\end{tabular}

Keterangan (Note): nm: tidak diukur (not measured)

\& Pirzan (2006) mengemukakan bahwa parameter bahan organik, $\mathrm{SO}_{4}$, dan Fe termasuk faktor penentu terhadap dinamika makrozoobentos dalam substrat dasar perairan. Lokasi tambak Maros yang memiliki bahan organik yang lebih tinggi dibandingkan lokasi lainnya dipengaruhi oleh lokasinya yang merupakan kawasan mangrove sehingga banyak daun mangrove yang gugur ke tambak dan menjadi serasah sebagaimana terlihat pada saat pengambilan sampel tanah. Pada lokasi Maros, kelimpahan makrozoobentos tidak diikuti dengan keanekaragaman yang tinggi sebagaiman yang ada pada lokasi Pangkep.
Makrobentos yang hidup di lingkungan mangrove khususnya dari golongan cacing Polychaeta, dapat digunakan untuk memprediksi peranan atau kontribusi ekosistem mangrove sebagai sumber atau stok pakan alami bagi lingkungan tambak rakyat yang ada di sekitarnya (Muhammad et al., 2013). Keberadaan makrozoobentos yang lebih banyak di lokasi Maros dan Pangkep dibandingkan dengan lokasi Polman yang ditunjang dengan kondisi kualitas air yang baik (khususnya salinitas) diduga merupakan salah satu faktor pendukung sehingga diperoleh produksi yang lebih banyak pada kedua lokasi tersebut dibandingkan dengan lokasi Polman (Tabel 3). Lokasi tambak yang

Tabel 3. Hasil pengamatan makrobentos, indeks keanekaragaman, indeks keseragaman, dan indeks dominansi pada ketiga lokasi

Table 3. Observation of macrobenthos, diversity index, homogenity index, and dominance index at three locations

\begin{tabular}{lccc}
\hline \multirow{2}{*}{ Jenis makrobentos (Kind of macrobenthos) } & \multicolumn{3}{c}{ Lokasi (Location) } \\
\cline { 2 - 5 } & Maros & Pangkep & Polman \\
\hline Assimnae & - & 4 & - \\
Cerithiopsis & - & - & 5 \\
Cheritidae & - & 49 & - \\
Columbellidae & 29 & - & - \\
Cacing tambak (Fishing worms) & - & 1 & - \\
Jenis trisipan (Type of mud snail) & - & 13 & - \\
Jenis tiram (Type of oyster) & - & 2 & - \\
\hline \multicolumn{1}{c}{ Parameter (Parameters) } & & & \\
\hline Indeks keanekaragaman (Diversity index ) (H') & $\mathbf{0}$ & $\mathbf{0 . 8 9}$ & $\mathbf{0}$ \\
Indeks keseragaman (Homogenity index ) (E) & $\mathbf{1}$ & $\mathbf{0 . 5 5}$ & $\mathbf{1}$ \\
Indeks dominansi (Dominance index ) (D) & $\mathbf{1}$ & $\mathbf{0 . 5 4}$ & $\mathbf{1}$ \\
\hline
\end{tabular}


memiliki kelimpahan makrozoobentos yang tinggi tetap disarankan untuk menyediakan pakan tambahan sesuai dengan dosis yang direkomendasikan $(5 \% 10 \%)$ untuk menunjang ketersediaan pakan dan juga meminimalisir terjadinya kanibalisme.

\section{Pertumbuhan, Sintasan, dan Produksi}

Kegiatan pembesaran krablet kepiting bakau hasil pembenihan pada tiga lokasi menunjukkan adanya variasi pada rata-rata bobot akhir dan sintasan (Tabel 4). Bo bot akhir rata-rata tertinggi diperoleh pada lokasi Pangkep yaitu 199,50 g (sintasan 36,94\% diikuti oleh Maros dengan bobot 158,96 g (sintasan 32,31\% dan terendah yaitu di Polman dengan bobot 130,95 g (sintasan 22\%. Rendahnya sintasan yang diperoleh pada kegiatan budidaya kepiting bakau sangat dipengaruhi oleh kanibalisme khususnya pada pemeliharaan dengan kepadatan tinggi sehingga perlu dilakukan upaya pemasangan shelter dan penyediaan pakan yang cukup. Lee $\&$ W ickins (1992) mengemukakan bahwa individu yang baru saja melakukan moulting rawan terhadap kanibalisme khususnya pada kondisi budidaya yang padat. Keberadaan shelter dan ketersediaan pakan yang cukup tidak mengeliminasi (menghilangkan) kanibalisme, meskipun ketiadaan dua hal tersebut dapat meningkatkan kanibalisme. Paterson \& Mann (2011) menyarankan untuk spesies Scylla dan kepiting perenang (swimming crab) lainnya ditebar pada kepadatan rendah (1 krablet $\left./ \mathrm{m}^{2}\right)$ untuk meningkatkan sintasan.

Hal yang cukup menarik adalah kepadatan yang rendah untuk daerah Polman $\left(0,27\right.$ ekor $\left./ \mathrm{m}^{2}\right)$ tidak menjadikan pertumbuhan dan juga sintasannya lebih baik dibandingkan dengan lokasi Maros yang memiliki kepadatan yang lebih tinggi $\left(0,53 \mathrm{ekor} / \mathrm{m}^{2}\right)$. Hal ini berbeda dengan hasil penelitian Rusdi et al. (1993) yang memelihara kepiting bakau di akuarium dengan kepadatan 4, 8, dan $12 \mathrm{ekor} / \mathrm{m}^{2}$ dan juga penelitian Gunarto \& Rusdi (1993) yang memelihara kepiting bakau (bobot awal \pm 50 g/ekor) di tambak dengan kepadatan 1, 3, dan 5 ekor $/ \mathrm{m}^{2}$, menunjukkan hasil yang lebih baik pada kepadatan yang lebih rendah dan berbeda nyata secara statistik $(P<0,05)$. Sintasan yang lebih rendah pada lokasi Polman dibandingkan dengan lokasi lainnya yang memiliki kepadatan yang lebih tinggi mungkin saja terjadi karena selain kepadatan dan ketersediaan pakan yang cukup, faktor lain yang cukup berpengaruh pada kegiatan budidaya kepiting bakau adalah kualitas air. Kondisi kualitas air yang baik khususnya salinitas merupakan hal yang cukup signifikan dalam memengaruhi pertumbuhan kepiting bakau yang dipelihara. Salinitas yang rendah $(<10$ ppt) atau tinggi (> $35 \mathrm{ppt}$ ) diduga dapat mengganggu siklus moulting sehingga pertumbuhan kurang maksimal dan dapat menyebabkan rendahnya produktivitas dan sintasan yang diperoleh. Pada hewan krustasea pertambahan ukurannya sangat ditentukan oleh seberapa sering dia melakukan moulting karena selama masa rentang antara moulting yang satu dengan moulting berikutnya kepiting bakau tidak bertambah ukuran namun hanya bertambah bobot. Salinitas yang rendah di daerah Polman yang disertai dengan ketidaklancaran penggantian air selama proses budidaya diduga berpengaruh terhadap rendahnya pertumbuhan yang diperoleh dibandingkan dengan lokasi lainnya. Berdasarkan hasil pertumbuhan, sintasan, dan produksi yang diperoleh (Tabel 4), keberhasilan pembesaran krablet di tambak, tergantung pada ketersediaan pakan yang cukup,

Tabel 4. Pertumbuhan, sintasan, dan produksi kepiting bakau yang dipelihara pada tiga lokasi tambak

Table 4. Growth, survival, and production of mud crab at the three different ponds

\begin{tabular}{|c|c|c|c|}
\hline \multirow{2}{*}{$\begin{array}{l}\text { Param eter } \\
\text { Parameters }\end{array}$} & \multicolumn{3}{|c|}{ Lokasi tambak (Pond locations) } \\
\hline & Maros & Pangkep & Polman \\
\hline Luas petakan (Pond area ) $\left(\mathrm{m}^{2}\right)$ & 800 & 5,000 & 2,800 \\
\hline Padat penebaran (ekor $\left./ \mathrm{m}^{2}\right) /$ Stocking density (ind. $\left./ \mathrm{m}^{2}\right)$ & 0.53 & 0.24 & 0.27 \\
\hline Masa pemeliharaan (hari) / Rearing periods (days) & 92 & 91 & 101 \\
\hline Bobot awal (g/ekor)/ Initial weight (g/ind.) & 0.1 & 0.05 & 0.1 \\
\hline Bobot akhir rata-rata (g/ekor) / Average final weight (g/ind.) & $158.96( \pm 46.94)$ & $199.50( \pm 64.01)$ & $131.05( \pm 34.25)$ \\
\hline Pertumbuhan mutlak (Absolute growth) $(\mathrm{g})$ & 158.86 & 199.45 & 130.95 \\
\hline Pertumbuhan harian (g/hari) / Daily growth (g/day) & 1.72 & 2.19 & 1.29 \\
\hline Laju pertumbuhan harian (Daily growth rate) (\%) & 8.01 & 8.21 & 7.11 \\
\hline Sintasan (Survival rate) (\%) & 32.31 & 36.94 & 22 \\
\hline Produksi (kg/petakan)/ Production (kg/plot) & 21.77 & 88.43 & 22.19 \\
\hline Produksi (Production) (kg/ha) & 272.12 & 176.86 & 79.25 \\
\hline
\end{tabular}


keberadaan shelter, pergantian air secara rutin dan kondisi kualitas air yang optimal; selain itu, produksinya dapat ditingkatkan melalui penambahan padat tebar sampai $1 \mathrm{ekor} / \mathrm{m}^{2}$.

\section{Analisis Usaha}

Hasil analisis usaha untuk ketiga lokasi setelah dikonversi keluasan hektar disajikan pada Tabel 5 dan 6. Perhitungan analisis usaha dimaksudkan sebagai bahan kajian untuk mengetahui sejauh mana prospek usaha pembesaran krablet kepiting bakau hasil pembenihan di tambak pada tiga lokasi dengan daya dukung yang berbeda. Adi (2011) mengemukakan bahwa analisis usaha perikanan budidaya bertujuan untuk mengetahui gambaran secara jelas modal atau investasi yang diperlukan untuk operasional suatu usaha kegiatan produksi tambak per musim tanam atau dalam satu tahun dan secara garis besar petani atau pelaku usaha perikanan dapat mengetahui penerimaan dan keuntungan yang diperoleh, serta beberapa lama kemungkinan modal investasi tersebut dapat dikembalikan.

Berdasarkan analisis usaha yang dilakukan maka usaha pembesaran kepiting bakau di tambak menggunakan krablet asal hatchery merupakan usaha yang layak yang dapat dilihat dari nilai R/C rasio yang lebih besar dari satu untuk semua lokasi. Pendapatan tertinggi diperoleh pada lokasi Maros yaitu Rp 5.454.750/ha/siklus, disusul oleh Pangkep dan Polman dengan pendapatan masing-masing Rp 4.624.400/ha/siklus dan Rp 317.150/ha/siklus. Nilai keuntungan setelah dikonversi keluasan hektar diperoleh keuntungan tertinggi pada lokasi Maros karena didukung dengan kepadatan awal yang lebih tinggi dibandingkan dua lokasi lainnya dan kondisi salinitas yang baik. Usaha pembesaran krablet kepiting

Tabel 5. Investasi dan pendapatan yang diperoleh pada ketiga lokasi setelah dikonversi keluasan hektar

Table 5. Investments and income analyses at the three location per one hectare pond area

\begin{tabular}{|c|c|c|c|c|}
\hline & Item & Maros (Rp) & Pangkep (Rp) & Polman (Rp) \\
\hline \multirow[t]{7}{*}{ A } & Investasi $(a+b)($ Investments $(a+b))$ & $10,851,250$ & $6,918,600$ & $6,345,350$ \\
\hline & a) Lahan dan peralatan (Land and equipment) & $3,000,000$ & $3,000,000$ & $3,000,000$ \\
\hline & - Lahan tambak (milik sendiri) (Pond (owned)) & 0 & 0 & 0 \\
\hline & - Waring hitam (Black hapa ) & $2,400,000$ & $2,400,000$ & $2,400,000$ \\
\hline & - Bambu (Bamboo) & 400,000 & 400,000 & 400,000 \\
\hline & - Sero, baskom, dan lain-lain (Scoop, basin, etc) & 200,000 & 200,000 & 200,000 \\
\hline & $\begin{array}{l}\text { b) Modal kerja (biaya variabel) } \\
\text { Working capital (Variable cost) }\end{array}$ & $7,851,250$ & $3,918,600$ & $3,345,350$ \\
\hline \multirow[t]{2}{*}{ B } & Biaya tetap (Fixed cost) & 300,000 & 300,000 & 300,000 \\
\hline & Penyusutan alat (Tools depreciation ) & 300,000 & 300,000 & 300,000 \\
\hline \multirow[t]{5}{*}{$\mathrm{C}$} & Biaya variabel (Nariable cost) & $7,851,250$ & $3,918,600$ & $2,345,350$ \\
\hline & $\begin{array}{l}\text { - Krablet kepiting bakau (@ Rp500,00/ekor) } \\
\text { Mud crab crablet (@ IDR 500/ind.) }\end{array}$ & $2,625,000$ & $1,200,000$ & $1,374,500$ \\
\hline & - Transportasi krablet (Crablet transportation) & 50,000 & 100,000 & 250,000 \\
\hline & $\begin{array}{l}\text { - Pakan (ikan rucah dan ikan liar di sekitar tambak) } \\
\text { Feed (trash fish and wild fish around the pond) }\end{array}$ & $4,676,250$ & $2,118,600$ & $1,220,850$ \\
\hline & $\begin{array}{l}\text { - Lain-lain (konsumsi dan upah panen) } \\
\text { Etc (consumption and harvest cost) }\end{array}$ & 500,000 & 500,000 & 500,000 \\
\hline D & $\begin{array}{l}\text { Total biaya produksi }(B+C) \\
\text { Cost production }(B+C)\end{array}$ & $8,151,250$ & $4,218,600$ & $3,645,350$ \\
\hline $\mathrm{E}$ & $\begin{array}{l}\text { Penjualan kepiting (Crab selling) } \\
\text { Jumlah panen }(\mathrm{kg}) \text { × Rp50.000,00 × } 1 \text { siklus } \\
\text { Yield }(\mathrm{kg}) \text { × IDR } 50,000 \times 1 \text { cycle }\end{array}$ & $13,606,000$ & $8,843,000$ & $3,962,500$ \\
\hline $\mathrm{F}$ & $\begin{array}{l}\text { Nilai produksi total (E) } \\
\text { Total production value (E) }\end{array}$ & $13,606,000$ & $8,843,000$ & $3,962,500$ \\
\hline G & $\begin{array}{l}\text { Keuntungan usaha total (F-D) } \\
\text { Total business profits (F-D) }\end{array}$ & 545,750 & $4,624,000$ & 317,150 \\
\hline
\end{tabular}


Tabel 6. Perbandingan analisis usaha pada ketiga lokasi setelah dikonversi keluasan hektar Table 6. Comparative business analysis at the three locations per one hectare pond area

\begin{tabular}{|c|c|c|c|}
\hline Uraian & Maros & Pangkep & Polman \\
\hline a Pendapatan (Income) & $13,606,000$ & $8,843,000$ & $3,962,500$ \\
\hline b Keuntungan (Profit) & $5,454,750$ & $4,624,400$ & 317,150 \\
\hline \multicolumn{4}{|l|}{ c Cash flow (arus kas) } \\
\hline $\begin{array}{l}\text { (Keuntungan }+ \text { penyusutan) } \\
\text { (Profit }+ \text { depreciation) }\end{array}$ & $5,754,750$ & $4,924,400$ & 617,150 \\
\hline \multicolumn{4}{|l|}{ d Rentabilitas ekonomi (Economic rentability) } \\
\hline $\begin{array}{l}\text { (Keuntungan/total investasi) } \times 100 \% \\
\text { (Profit/total investment) } \times 100 \%\end{array}$ & 50 & 67 & 5 \\
\hline \multicolumn{4}{|l|}{ e Pay back period } \\
\hline $\begin{array}{l}\text { (Total biaya invest/cash flow) } \\
\text { (Total investment/cash flow) }\end{array}$ & 1.89 & 1.4 & 10.28 \\
\hline \multicolumn{4}{|l|}{ f Break event point (BEP) harga (Price) (Rp) } \\
\hline $\begin{array}{l}\text { (Total biaya produksi/total produksi (kg)) } \\
\text { (Cost production/production total (kg)) }\end{array}$ & 30,231 & 23,852 & 46,021 \\
\hline \multicolumn{4}{|l|}{ g Break event point (BEP) volume (volume) (kg) } \\
\hline $\begin{array}{l}\text { (Total biaya produksi/harga jual per kg) } \\
\text { (Cost production/selling price per kg) }\end{array}$ & 163 & 84 & 73 \\
\hline $\begin{array}{l}\text { h R/C rasio (biaya penerimaan/biaya produksi) } \\
\text { R/C ratio (Crab selling/production cost) }\end{array}$ & 1.67 & 2.1 & 1.09 \\
\hline
\end{tabular}
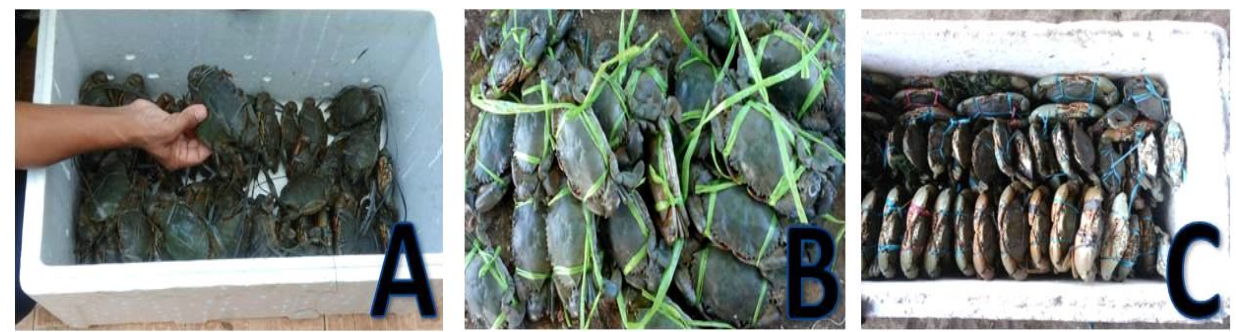

Gambar 3. Kepiting bakau hasil panen pada tiga lokasi; A) Maros, B) Pangkep, C) Polman.

Figure 3. Mud crab harvest at the three locations; A) Maros, B) Pangkep, C) Polman.

bakau hasil pembenihan di tambak memiliki prospek yang cukup baik meskipun masih membutuhkan banyak kajian untuk pengembangannya, terutama upaya meminimalisasi kanibalisme dan meningkatkan pendapatan yang diperoleh melalui perbaikan teknik budidaya dan penerapan sistem polikultur.

\section{KESIMPULAN}

Bobot akhir rata-rata yang diperoleh pada ketiga lokasi untuk masa pemeliharaan selama tiga bulan berkisar 131.05-199.50 g/ekor $(163,17 \pm 34,42)$, sintasan $22 \% 36,94 \%(30,41 \pm 7,65)$ dan produksi $79,25-272,12 \mathrm{~kg} / \mathrm{ha}(176,07 \pm 96,43)$. Keuntungan tertinggi diperoleh pada lokasi Maros yaitu Rp5.454.750/ha/siklus kemudian lokasi Pangkep yaitu Rp4.624.400/ha/siklus dan terendah di lokasi Polman yaitu Rp317.150,00/ha/siklus. Nilai R/C rasio untuk semua lokasi menunjukkan lebih besar dari satu yang berarti bahwa usaha pembesaran kepiting bakau di tambak menggunakan krablet asal hatchery merupakan usaha yang layak.

\section{UCAPAN TERIMA KASIH}

Ucapan terima kasih disampaikan kepada segenap tim pembenihan kepiting bakau di Instalasi Tambak Percobaan Marana dan juga kepada para pembudidaya 
yang terlibat di tiga lokasi. Kegiatan ini dibiayai dana penelitian Balai Penelitian Perikanan Budidaya Air Payau yang bersumber dari APBN 2016 dengan penanggung jawab kegiatan Bapak Drs. Gunarto, M.S.

\section{DAFTAR ACUAN}

Adi, V.Ap.S. (2011). Analisis usaha perikanan budidaya. Balai Besar Pengembangan Budidaya Air Payau. Jepara, $44 \mathrm{hlm}$.

Arnold, P.W., \& Birtles, R.A. (1989). Soft-sediment marine invertebrates of Southest Asia and Australia: A guide to identification. Australian Institute of Marine Science. Australia, 272 pp.

Gunarto, \& Rusdi, I. (1993). Budidaya kepiting bakau Scylla serrata di tambak pada padat penebaran berbeda. Jurnal Penelitian Budidaya Pantai, 9(3), 7 12.

Gunarto, \& Syafaat, M.N. (2015). Budidaya pembesaran kepiting bakau di tambak bakau. Dalam Rosmiati, Jompa, H., Rangka, N.A., Pirzan, M., \& Natsir, R. Laporan tahunan Balai Penelitian dan Pengembangan Budidaya Air Payau Tahun 2014. Maros, hlm. 38-41.

Gunarto, Syafaat, M.N., Herlinah, Parenrengi, A., \& Mustafa, A. (2016). Aspek biologi dan teknik produksi benih kepiting bakau Scylla spp. Badan Penelitian dan Pengembangan Kelautan dan Perikanan, Kementerian Kelautan dan Perikanan. Jakarta, $62 \mathrm{hlm}$.

Hendrajat, E.A., \& Gunarto. (2013). Pertumbuhan kepiting bakau (Scylla olivacea dan Scylla paramamosain) hasil pembenihan Balai Penelitian dan Pengembangan Budidaya Air Payau Maros. Prosiding Seminar Nasional Tahunan X Hasil Penelitian Perikanan dan Kelautan Tahun 2013. Jurusan Perikanan dan Kelautan, Fakultas Pertanian, Universitas Gadjah Mada. Jogjakarta, pRB 08-6 hlm.

Herlinah, Sulaeman, \& Tenriulo, A. (2010). Pembesaran kepiting bakau (Scylla serrata) di tambak dengan pemberian pakan berbeda. Prosiding Forum Inovasi Teknologi Akuakultur, hlm. 169-174.

Lee, D.O'C., \& Wickins, J.F. (1992). Crustacean farming. New York: John Wiley \& Sons,Inc., 392 pp.

Lekang, O.I. (2013). Aquaculture engineering. Second edition. UK: Wiley-Blackwell, John Wiley \& Sons, Ltd.

Muchlisin, Z.A., \& Azizah, M.N.S. (2009). Alternative feeds and daily rations for mud crab (Scylla serrata F.) culture. Proceeding of the Asia Pacific Aquaculture Conference. Kuala Lumpur, Malaysia.

Muchlisin, Z.A., Rudi, E., Muhammad, \& Setiawan, I. (2006). Pengaruh perbedaan jenis pakan dan ransum harian terhadap pertumbuhan dan kelangsungan hidup kepiting bakau (Scylla serrata). IImu Kelautan, II(4), 227-233.

Muhammad, F., Hidayat, J.W., \& Mukid, M.A. (2013). Aplikasi bio-ekologi makrobenthos sebagai indikator tingkat kesuburan tambak. Jurnal Sains dan Matematika, 21(3),75-83.

Paterson, B.D., \& Mann, D.L. (2011). Mud crab aquaculture, in Recent advances and new species in aquaculture. Fotedar, R.K., \& Phillips, B.F. (Eds.). UK: Wiley-Blackwell, Oxford, (p. 115-135.

Permadi, S., \& Juwana, S. (2014). Kajian awal pembesaran benih kepiting bakau Scylla paramamosain asal laboratorium menggunakan keramba jaring dasar. Oseanologi dan Limnologi di Indonesia 2014, 40(2), 211-220.

Permadi, S., \& Juwana, S. (2016). Penetapan kebutuhan harian pakan ikan rucah untuk penggemukan kepiting bakau Scylla paramamosain di keramba jaring dasar. Oseanologi dan Limnologi di Indonesia, $1(1), 75-83$.

Pillai, S.L., Rajapackiam, S., \& Sunderarajan, D. (2002). Mud crab Scylla tranquebarica culture in earthen pond at Tuticorin. J. Mar. biol. Ass. India, 44(1\&2), 245-248.

Pong-masak, P.R., \& Pirzan, M. (2006). Komunitas makrozoobentos pada kawasan budidaya tambak di pesisir Malakosa Parigi-Moutong, Sulawesi Tengah. Biodiversitas, 7(4), 354-360.

Qomariyah, L., Samidjan, I., \& Rachmawati, D. (2014). Pengaruh persentase jumlah pakan buatan yang berbeda terhadap pertumbuhan dan kelulusan hidupan kepiting bakau (Scylla paramamosain). Journal of Aquaculture M anagement and Technology, 3(4), 18-25.

Rusdi, I., Pantjara, B., \& Cholik, F. (1993). Pengaruh perbedaan padat penebaran dan jumlah naungan terhadap kelangsungan hidup kepiting bakau, Scylla serrata dalam kondisi laboratorium. Jurnal Penelitian Budidaya Pantai, 9(1), 135-139.

Shelley, C., \& Lovatelli, A. (2011). Mud crab aquaculture: A practical manual FAO Fisheries and aquaculture technical paper No.567. Rome, $78 \mathrm{pp}$.

Smith, R.I., \& Carlton, J.T. (1975). Light's manual: Intertidal invertebrates of the central california coast. University of California press, $716 \mathrm{pp}$.

Sulaeman, Widodo, A.F., \& Herlinah. (2010). Polikultur kepiting bakau (Scylla serrata) dan rumput laut (Gracillaria verrucosa) dengan metode tebar yang berbeda. Prosiding Forum Inovasi Teknologi Akuakultur, hlm. 211-219. 
Syafaat, M.N., Pantjara, B., \& Rangka, N.A. (2013). Aklimatisasi benih nila merah (0. niloticus) toleran salinitas tinggi siap tebar menggunakan wadah yang berbeda dengan kepadatan tinggi. Prosiding Forum Inovasi Teknologi Akuakultur 2013, hlm. 79-85.
Widodo, A.F., Sulaeman, \& Jompa, H. (2010). Pembesaran kepiting bakau, Scylla serrata, di lahan mangrove dengan sistem silvo-fishery. Prosiding Seminar Nasional Limnologi V, hlm. 750-759. 